\title{
Tractor and Semitrailer Routing Problem of Highway Port Networks under Unbalanced Demand
}

\author{
Hongxia GUO, Shaoquan $\mathrm{Nl}^{*}$
}

\begin{abstract}
In China, highway port networks are essential in carrying out tractor and semitrailer transportation operations. To analyze the characteristics of tractor and semitrailer routing in highway port networks, this study examined the situation in which the demands at both ends of the operation might be unbalanced and multiple requirements might be raised in the operation of tractor and semitrailer transportation. An optimal tractor and semitrailer routing model for an entire network was established to reduce the total transportation costs and the number of towing vehicles in the network. Moreover, a heuristic algorithm was designed to solve the model. The comparisons of Strategy 1 and Strategy 2 for a two-stage network swap trailer show that the number of pure network swaps trailer tractors decreases by $21.6 \%$ and $18.6 \%$, respectively; and that the cost drops by $7.8 \%$ and $7.9 \%$, respectively. In other words, swap trailer transport enterprises can abandon the original swap trailer transportation mode for a two-stage network and adopt a routing optimization strategy for an entire network to achieve superior operation performance, reduce costs, and enhance profits. The study provides a reference for optimizing tractor and semitrailer routing in highway port networks with balanced and multiple demands.
\end{abstract}

Keywords: highway port; road port networks; scheduling optimization; truck and trailer transportation; unbalanced demand

\section{INTRODUCTION}

In the 1960s, swap trailer transport via combination vehicles was widely used in multiple fields, such as intercity trunk transportation, urban distribution, and multimodal transport in developed countries. Relative to trucks, combination vehicles can complete swap trailer transport by freely separating and combining the power and cargo carry parts so as to enhance vehicle use efficiency [1, 2].

Multiple types of combination vehicles (e.g., trucktrailer and truck-semitrailer vehicles) are allowed in many countries. However, China's existing policies restrict the form of combination vehicles in swap trailer transport. Only tractor-semitrailer vehicles are allowed on Chinese roads, and truck-trailer vehicles are forbidden. Specifically, the power part of a combination vehicle is not allowed to carry any load. Therefore, the study and application of swap trailer transport in China is quite different from that in Europe and America. With its diverse vehicles, swap trailer transport is widely used in intercity trunk transportation and urban distribution in foreign countries. At present, the characteristics of the vehicle types that can be used by Chinese swap trailer transport enterprises indicate that swap trailer transport is mainly used in intercity trunk transportation. Scholars hold that the routing of combination vehicles is complicated and is an NP-hard problem. This problem has brought great challenges to the routing of swap trailer transport on intercity trunk lines.

Accordingly, scholars have carried out numerous studies on the tractor and semitrailer routing problem (TSRP) in intercity trunk transportation networks [3-5]. The main assumption is that customers have certain demands, that is, swap trailer vehicles only need to visit customers once to meet the requirements of goods distribution or garbage collection. In swap trailer transport in a highway port network, transportation is completed between highway ports, which function not only as the site of swap trailer operation but also as the customer demand point. Different from the demands in general swap trailer transport, the demands in swap trailer transport in highway ports take trailer as the unit. Multiple trailers may be demanded, and the demands at both ends of a swap trailer may be different. Multiple modes of swap trailer transport exist between two highway ports, and the demands at both ends of the swap trailer transport are unbalanced, thereby making the routing optimization of swap trailer transport increasingly complicated. Hence, a swap trailer transport routing model between road ports should be established, and a suitable vehicle routing mode should be developed. In this study, we establish a swap trailer routing optimization model for an entire network according to the characteristics of swap trailer transport in road port networks. The model is built under the assumption that customers have demands for multiple swap trailers and that the demands at both ends of swap trailer transport are unbalanced. The results of this work can provide a reference for optimizing swap trailer transport in road port networks.

On the basis of the unbalanced demands at both ends of swap trailer transport and the demands for multiple swap trailers, a swap trailer routing model for an entire network was established to minimize the total transportation cost and number of tractors. A heuristic algorithm was designed to solve the model. The effectiveness of the model was verified with Tiandihui as an example. This study aims to satisfy customers' demands for multiple modes of swap trailer transport and solve the problem of unbalanced vehicle routing at both ends so as to provide a reference for the routing of swap trailer transport in road port networks.

\section{STATE OF THE ART}

Swap trailer transport routing is a vehicle routing problem (VRP), but it is more complicated than the general VRP due to the presence of trailer vehicles.

Swap trailer transport can be applied to many scenarios. In 1993, Semet, F. [6] first proposed to apply swap trailer transport to goods distribution in grocery stores, but the study failed to consider constraints such as time windows. The designed algorithm required further improvement. L. De Meulemeester et al. [7] applied swap trailer transport to garbage collection and transportation for 
the first time in 1997 and took a swap trailer transport enterprise in Belgium with 160 clients as an example. The algorithm they designed could yield results in $1 \mathrm{~min}$, but the object of the study was only limited to industrial enterprises in Belgium. In 2014, Mikhail et al. [8] applied swap trailer transport to goods distribution from warehouses to multiple stores. Their algorithm considers soft and hard time windows and inconsistent vehicle models, it achieved satisfactory results in the study.

In their studies on swap trailer transport routing, scholars have mainly focused on the problems existing in swap trailer transport. Moreover, corresponding mathematical models have been established and solved by designing heuristic algorithms so as to provide support for decision making related to swap trailer transport routing. In 2002, Chao [9] proposed and comprehensively defined the truck and trailer routing problem (TTRP). He designed a tabu search algorithm to effectively solve the TTRP but failed to consider constraints such as the number of vehicles and time windows. On the basis of Chao's study, a number of scholars have designed various heuristic algorithms to improve the calculation efficiency and accuracy under constraints such as the number of vehicles and time windows. In 2016, Isis [10] modified the TTRP model and introduced the ability and constraints of customer fuzzy requirements to achieve good calculation results; however, the model should be further improved. In 2017, Isis [11] improved the TTRP model and used a data mining algorithm to derive a decision tree that could determine the best comparison method according to the characteristics of the TTRP. However, the two models proposed by Isis did not consider the constraint of time windows. Peng Yong et al. [12] dicussed the problem of multi-trip container-exchanging drop-shipping with a time window for urban-suburban logistics distribution systems in oder to minimize transportation costs and increase customer satisfaction. Considering the swap trailer routing of tractors that could drag trailers with different tonnages, Yang Zhenhua et al. [13] designed a hybrid simulation annealing algorithm and proposed that the crossed swap trailer of multiple vehicles had the advantage of cost savings; however, the method was not suitable for the joint optimization of multiple vehicle task allocation and routing based on freight volume. Parragh et al. [14] put forward the branch-and-price algorithm to solve the TTRPTW problem while considering the constraint of time windows; however, the pricing scheme was simple. Toffolo et al. [15] divided customers into three categories: customers whose goods could only be delivered by trucks, customers whose goods could be delivered by trucks and combination vehicles, and customers whose goods can only be delivered by combination vehicles. A random local search algorithm was designed to solve the proposed SB-VRP (similar to the TTRP). However, the designed algorithm was complex and involves a large number of neighborhoods; these drawbacks influence the application of the algorithm to other problems. Wang et al. developed [16] an adaptive bat algorithm to solve the TTRP and designed five domain search structures in local search. An adaptive adjustment strategy was also designed to preserve the diversity of particles. The accuracy and efficiency of the algorithm were verified using 21 benchmark problems, but the constraint of customer time window was neglected. To solve the TTRP, Wang Chao et al. [17] proposed an iterative variable neighborhood descent algorithm. By comparing this algorithm with four other algorithms in the literature, the authors reported that the proposed IVND algorithm could converge to a satisfactory solution in the shortest calculation time. Moreover, the IVND algorithm had the advantages of simple structure, high calculation efficiency, and easy implementation. Therefore, it could be flexibly extended to solve other VRPs and combination optimization problems. The disadvantage of the IVND algorithm is that the run time of neighborhood operators occupies a large proportion and that the service time window is neglected. E.Bartoliniet al. [18] proposed a twocommodity flow formulation for the CTTRP, and used two sets of flow variables to model the flow of goods carried by trucks pulling a trailer and by trucks alone, respectively. They described valid inequalities for strengthening the formulation and also developed a branch-and-cut algorithm for solving it.

The studies on the TSRP can be classified into two categories: roller-roll off vehicle routing problem (RRVRP) and tractor and semitrailer routing problem (TSRP). As the study of Li et al. [19] suggested, RRVRP is a development of the VRP and is one of three main garbage collection businesses. The basic RRVRP has a single station. At the beginning of the day, all tractors stop at the station. As no garbage disposal equipment is available, trailers dump garbage at the station, and the empty trailers are subsequently towed away. At the end of the day, all tractors return to the station while the trailers stay at the customer nodes or garbage disposal equipment. The operation mode of garbage trucks is similar to that of combination vehicles of tractors and semitrailers. The power and cargo parts of a garbage truck with a detachable carriage correspond to a tractor and semitrailer, respectively. $\mathrm{Li}$ et al. [20] used a route decomposition algorithm to transform a route into arc requirements and established a vehicle flow planning model of the RRVRP, which they solved by developing an improved C-W saving algorithm with local search. However, the constraint of time window was not considered. To solve the practical problems of container transportation, Li [21] put forward the generalized RRVRP, which is not applicable to multiple warehouses and open routes. As argued by Xu et al. [22] result planning can only solve small-scale transportation problems. For large-scale transportation problems, they developed the maximum and minimum ant colony optimization algorithm to reduce the calculation time. They considered that empty containers need to be transported back to the dock after customers open their packages, but they failed to take container sharing into account. Although the overall efficiency of the system was enhanced, model construction became considerably complex. Berghman and Leus [23] studied a distribution warehouse in which the trailers were assigned to the dock for loading or unloading. The transportation between the parking lot and the dock was completed by tractors. The primary objective of optimization was to form a docking plan to minimize the delay of late trailers. The secondary objective was to minimize the weighted completion time of the entry and exit of trailers. Four methods were used to solve the problem: mathematical programming, branch and 
bound method, beam search process, and tabu search algorithm [24]. The studies on the TSRP have mainly focused on VRPs and TTRPs. Li Hongqi et al. [25] studied the TSRP with time window constraints and proposed a heuristic algorithm to solve the TSRP on the basis of savings and neighborhood search. The designed algorithm and its results needed to be improved. $\mathrm{Yu} \mathrm{Li}$ et al. [26] investigated a multi-depot TSRP in a network mode and considered the routing of empty trailers. However, the number of trailers at each service point was assumed to be unchanged, leading to limitations in network routing. The algorithm was not applicable to one-tractor or multi-trailer swap trailer transport and routing problems in dynamic conditions. Yang Guangmin et al.[27] established a container swap trailer transport routing model in a huband-spoke network structure and designed a heuristic algorithm. This solution could effectively improve the solving speed. However, it was not applicable to routing in other transportation networks. To solve the problem of container swap trailer transport routing in hub-and-spoke networks, they considered different types of tasks, the numbers and locations of trailer centers, and the task time windows in swap trailer transport. They then developed an optimization mathematical model of swap trailer transport routing. A three-stage heuristic algorithm based on task urgency function, penalty function, and distance function was designed to schedule urgent tasks, ordinary tasks, and overdue tasks, respectively. By solving the classical examples, the authors changed the number of tractors, trailers, trailer centers and urgent tasks through sensitivity analysis to determine the influence of different factors on the overall routing scheme. This method could provide relevant decision support for the routing decision makers of swap trailer transport enterprises. However, it did not consider the problem in which tractors run from the opposite direction and drivers return after meeting.This study shows the experience of creating a BIM model from Reality Capture data. Users can navigate around the model and check for the information to make the best decisions possible to operate and maintain assets during their life or at the decommissioning stage [28-29].

In summary, trucks continue to meet customers' demands after dumping their trailers to meet the needs of multilevel customers. Hence, a large number of studies have focused primarily on truck-trailer vehicles. The study on tractor-semitrailer vehicles is scarce, and a significant difference exists between research scenarios and the actual transportation in a highway port network. According to the characteristics of the tractor and semitrailer transportation of highway ports in China and considering the unbalanced demands at both ends of a transportation network, this study established an optimization model for tractor and semitrailer transportation routing in a highway port network and designed a heuristic algorithm to solve the model. The results provide a reference for improving the tractor and semitrailer transportation routing efficiency in highway port networks.

This study is organized as follows. Section 3 describes the problems, establishes a mathematical model, and designs a heuristic algorithm to solve the model. Section 4 presents a case study. Taking the highway port network of a Chinese enterprise as an example, this study compares the costs and numbers of vehicles in different modes.
Section 5 summarizes this study and draws relevant conclusions.

\section{METHODOLOGY \\ 3.1 Description of Issues}

Maximizing the advantages of highway ports is necessary to form a network of lines. By renting or building a highway port site, an enterprise can carry out tractor and semitrailer transportation across several highway ports in many large and midsize cities. A highway port network is designed not only as a vehicle yard for tractors and trailers but also as the demand point for tractor and semitrailer transportation. As shown in Fig. 3, all ends of two highway ports are connected, and a network is formed between multiple highway ports. As a result of unbalanced demands for tractors and semitrailers, some demands greater than 1 . The numbers beside the tractor in Fig. 1 indicate the demand for truck and semitrailer transport in a certain direction. Truck and semitrailer transportation is not a simple one-line two-point or one-line multipoint routing operation; rather, it is routing in an entire network to meet different demands.

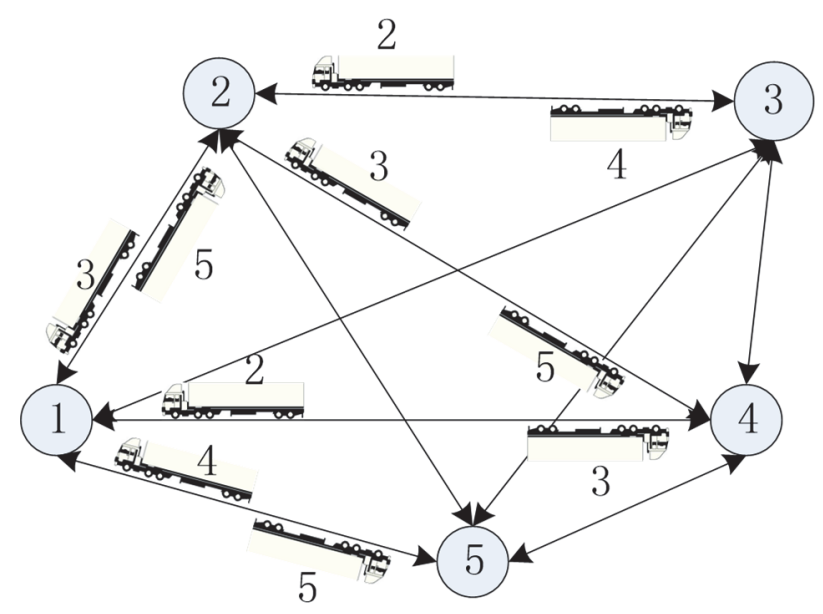

Figure 1 Diagram of highway port network transport

3

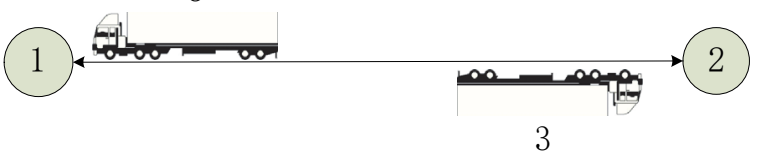

Figure 2 Phase 1: One line with two points

To ensure the stability of a certain tractor and semitrailer transportation line, an enterprise usually arranges a number of vehicles to be engaged in tractor and semitrailer transportation between two points while scheduling other vehicles to complete other tasks. Tractor and semitrailer transportation in a highway port network is divided into two phases.

Phase 1: One-line two-point truck and trailer transportation is shown in Fig. 2. This type is a relatively simple truck and trailer mode in which drivers frequently travel between two points and are thus aware of road conditions; this characteristic helps reduce accidents. Therefore, every two points in an entire network are independent. Given the unbalance between two points, the lowest demand quantity in two directions is taken as the operation amount of the one-line two-point model. The 
demands in a certain direction are satisfied. If the demands in the other direction are not met, they are moved to the next stage. For example, the number next to the semitrailer in Fig. 3 indicates the demand for tractor and semitrailer transportation, that is, five tractors are needed from point 1 to point 2, three tractors are needed from point 2 to point 1 , and the demands between point 1 and point 2 are unbalanced. The small number demanded between two points, namely, three tractors, is taken as the tractor and semitrailer operation quantity. The demand from point 2 to point 1 is satisfied, but two tractors are still needed from point 1 to point 2 . Therefore, the tractors in the entire network need to be scheduled to move to the next stage.

Phase 2: The cycled tractor and semitrailer transportation in the entire network is described in Fig. 5. After the routing in phase 1, the demand in one direction between two points is not satisfied, and scheduling in the entire network needs to be carried out. As shown in Fig. 5, two tractors are to be transported from point 1 to point 2 , one tractor from point 1 to point 4 , one tractor from point 1 to point 5 , one tractor from point 2 to point 3 , and two tractors from point 2 to point 4 . As the daily working time of one tractor is limited, the scheduling scheme with the lowest cost and the smallest number of tractors should be adopted at this phase.

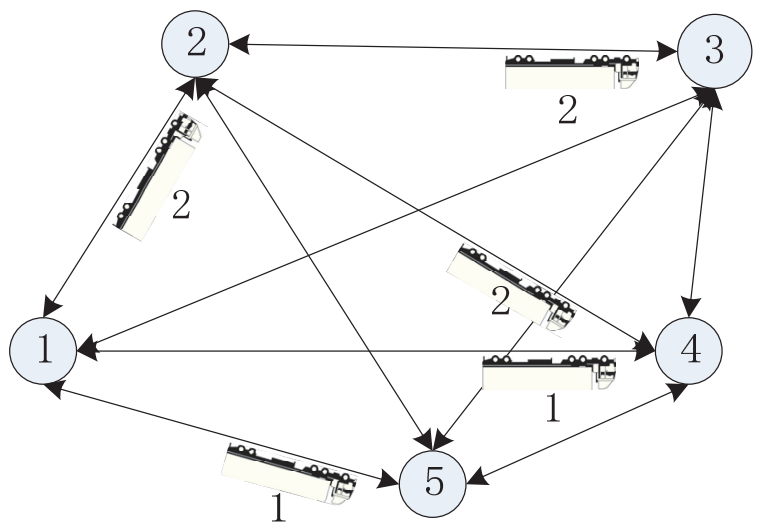

Figure 3 Phase 2: Cycled tractor and semitrailer transportation for the entire network

\subsection{Model Assumptions}

According to the characteristics of the tractor and semitrailer transportation in the highway port network, the following assumptions are made:

(1) All tractors and semitrailers in the network belong to the same standard model.

(2) The number of semitrailers in each highway port in the network is sufficient. This assumption can be achieved by integrating social resources with enterprises dealing with highway port tractor and semitrailer transportation.

(3) The working time of uploading and downloading semitrailers is not considered. Moreover, the number of semitrailers is assumed to be sufficient, thereby eliminating the need for the semitrailers to be loaded and unloaded.

(4) The distance and time of transportation between two highway ports are the same.

(5) Tractor and semitrailer transportation is needed every day in the network, and the demand fluctuates daily.
The enterprise can arrange the routing according to the actual daily demand. Given the long distance between certain nodes, the tractor and semitrailer transportation operations cannot be completed in one day. Therefore, the uncompleted task on the previous day is assumed to have no effect on the subsequent scheduling.

\subsection{Symbolic Description}

$N$ : a collection of all highway ports, $N=\{1,2, \ldots, n\}$.

$i, j, l$ : the number of highway ports, $i, j, l \in N$.

$K$ : a collection of tractors, $K=\{1,2, \ldots, k\}$, with $k$ also indicating the total number of tractors needed in the road network.

$k$ : the number of tractors, $k \in K$.

$d_{i j}$ : the distance between highway ports $i$ and $j$ (unit: $\mathrm{km})$.

$q_{i j}$ : the demand for tractor and semitrailer transportation from highway ports $i$ to $j$ and is expressed by the number of times. As the demand is not always balanced, $q_{i j}$ is not necessarily equal to $q_{j i}$.

$C_{i j}, c_{i j}$ : the costs of loading and unloading (unit: yuan $/ \mathrm{km})$.

$c$ : the fixed cost of the tractor per unit time, including the depreciation of vehicles and the wages of employees (unit: yuan).

$T$ : the continuous operation time of the tractor. All tractors are required to work continuously for equal periods of time each day.

$v_{1}, v_{2}$ : the speed at which the tractor is loaded and unloaded (unit: $\mathrm{km} / \mathrm{h}$ ).

$k_{1}, k_{2}$ : the state of being loaded and unloaded, respectively, $k \in K$.

$i j k_{1}$ : loaded tractor $k$ from the highway point $i$ to $j$.

$i j k_{2}$ : unloaded tractor $k$ from the highway point $i$ to $j$.

$x_{i j k 1}=\left\{\begin{array}{l}1 \\ 0\end{array}\right\}, x_{i j k 2}=\left\{\begin{array}{l}1 \\ 0\end{array}\right\}$

$x_{i j k 1}, x_{i j k 2}=1$, means that the tractor $k$ is loaded or unloaded from the highway point $i$ to $j$

$x_{i j k 1}, x_{i j k 2}=0$, means other circumstances

$a_{i j k 1}, a_{i j k 2}$ : the number of trips of tractor $k$ from highway port $i$ to highway port $j$ in loaded and unloaded driving states, respectively (unit: yuan $/ \mathrm{km}$ ).

\subsection{Mathematical Model}

Tractor and semitrailer transportation enterprises seek to minimize the cost according to the actual operation of the highway port network. Meanwhile, the number of tractors inputted is the smallest.

Objective 1: The operation cost is composed of the loaded cost, unloaded cost, and fixed cost. The loaded cost is as follows:

$$
Z_{l}=\sum_{i=1}^{n} \sum_{j=1}^{n} \sum_{k \in K} a_{i j k_{1}} d_{i j} C_{i j} x_{i j k_{1}}
$$

The unloaded cost is as follows: 


$$
Z_{u}=\sum_{i=1}^{n} \sum_{j=1}^{n} \sum_{k \in K} a_{i j k_{2}} d_{i j} c_{i j} x_{i j k_{2}}
$$

The daily fixed cost of using the vehicle is $Z_{\mathrm{c}}=K_{\mathrm{c}}$.

The goal is the minimum operating cost as follows:

$\min Z_{1}=$

$$
=\sum_{i=1}^{n} \sum_{j=1}^{n} \sum_{k \in K} a_{i j k_{1}} d_{i j} C_{i j} x_{i j k_{1}}+\sum_{i=1}^{n} \sum_{j=1}^{n} \sum_{k \in K} a_{i j k_{2}} d_{i j} c_{i j} x_{i j k_{2}}+K_{\mathrm{c}}
$$

Objective 2: The least number of tractors, which can be expressed as follows:

$\min Z_{2}=K$

The demand for tractor and semitrailer transportation is satisfied as $\sum_{k \in K} a_{i j k_{1}} x_{i j k_{1}}=q_{i j}$.

The continuous operation time of the tractor is $\frac{\sum_{i=1}^{n} \sum_{j=1}^{n} d_{i j} x_{i j k_{1}}}{v_{1}}+\frac{\sum_{i=1}^{n} \sum_{j=1}^{n} d_{i j} x_{i j k_{2}}}{v_{2}} \leq T$.

Note that the scheduling of tractor and semitrailer transportation with unbalanced demands is a doubleobjective problem. Objective 1 seeks to minimize the operation costs as all demands for tractor and semitrailer transportation must be met. Therefore, under this objective, the main trade-off exists between the unloaded driving cost and the fixed cost. The fixed cost $K_{\mathrm{c}}$ of the tractor is directly proportional to the number of tractors inputted $K$. If the unloaded driving cost is greater than the fixed cost, then the investment in the tractors increases while the overall operation cost decreases; this scenario contradicts Objective 2. If the unloaded driving cost is less than the fixed cost, then the unloaded tractor schedule is arranged without increasing the number of tractor input. This scenario is in line with Objective 2 . In this case, only the non-inferior solutions that satisfy Objectives 1 and 2 can be obtained. The demand for tractor and semitrailer transportation in the whole network is $\sum_{i=1}^{n} \sum_{j=1}^{n} q_{i j}$. If a tractor is arranged for each demand for tractor and semitrailer transportation, then $0 \leq K \leq \sum_{i=1}^{n} \sum_{j=1}^{n} q_{i j}$; that is, Objective 2 can become a constraint for Objective 1 .

Hence, the scheduling of tractor and semitrailer transportation based on unbalanced demand changes as follows:

$$
\begin{aligned}
& \min Z_{1}= \\
& =\sum_{i=1}^{n} \sum_{j=1}^{n} \sum_{k \in K} a_{i j k_{1}} d_{i j} C_{i j} x_{i j k_{1}}+\sum_{i=1}^{n} \sum_{j=1}^{n} \sum_{k \in K} a_{i j k_{2}} d_{i j} c_{i j} x_{i j k_{2}}+K_{\mathrm{c}}
\end{aligned}
$$

$$
\sum_{k \in K} a_{i j k_{1}} x_{i j k_{1}}=q_{i j}
$$

$$
\frac{\sum_{i=1}^{n} \sum_{j=1}^{n} d_{i j} x_{i j k_{1}}}{v_{1}}+\frac{\sum_{i=1}^{n} \sum_{j=1}^{n} d_{i j} x_{i j k_{2}}}{v_{2}} \leq T
$$

$$
0 \leq K \leq \sum_{i=1}^{n} \sum_{j=1}^{n} q_{i j}
$$

\subsection{Two-Stage Heuristic Algorithm 3.5.1 Algorithm}

The tractor and semitrailer transportation scheduling of a highway port network with unbalanced demands is essentially a vehicle scheduling problem with multiple depots. Each highway port can be regarded as a depot and as a customer. Therefore, it is also a special scheduling problem with the coincidence of the depot and demand point. As the starting point or the final point of the vehicle cannot be determined, several paths are available throughout any highway port network, thus making the problem increasingly difficult to solve. Scheduling can be carried out throughout the network, and the demand $q_{i j}$ between any two highway ports can be divided into two parts $q_{i j}^{\prime}$ according to common practice; $q^{\prime \prime}{ }_{i j}$ separation is not considered in pure tractor and semitrailer transportation operation network. If $q_{i j} \geq q_{j i}$, then $q_{i j}^{\prime}=q_{j i}=q_{j i}^{\prime}, q_{i j}^{\prime \prime}=q_{i j}$ $q_{j i}$, and $q^{\prime \prime}{ }_{i j}=0, q^{\prime \prime}{ }_{j i}=0$. If $q_{i j}<q_{j i}$, then $q_{i j}^{\prime}=q_{i j}=q_{j i}^{\prime}, q^{\prime \prime}{ }_{i j}=$ 0 , and $q_{i j}^{\prime \prime}=q_{j i}-q_{i j}, q_{i j}^{\prime}$. The matrix is a symmetric matrix. As for the demand for $q_{i j}^{\prime}$ and $q^{\prime \prime}{ }_{i j}$, a two-stage heuristic algorithm is designed to solve the problem.

Stage 1: Scheduling of tractor and semitrailer vehicles between two points of a line.

Only $q_{i j}^{\prime}$ needs to be scheduled at this stage. A highway port in the network is selected, and the task of tractor and semitrailer transportation is assigned to tractors. The tractors can be used fully loaded, and they can travel back and forth between the two highway ports. If the distance between $i$ and $k$ of highway port $d_{i j}$ is long, then the tractors can complete only one trip within the working time $T$ of the day (based on the assumption that one uncompleted trip is calculated as one trip), and $2 q_{i j}$ tractors are needed between $i$ and $j$ of the highway port. If the distance between $i$ and $j$ of highway port $d_{i j}$ is short and tractor $k$ can carry out multiple trips within working time $T$ in one day, then the traction trip that can be completed in time $T$ is given as follows:

$$
a_{i j k}^{\prime}=\left\lceil\frac{T}{d_{i j} / v_{1}}\right\rceil=\left\lceil\frac{T v_{1}}{d_{i j}}\right\rceil \text { while fully using the working }
$$

time, where \lceil\rceil represents upward rounding. If $a_{i j k}^{\prime}>2 q^{\prime}{ }_{i j}$ $=q_{i j}^{\prime}+q_{j i}^{\prime}$ then the kth one can complete all tasks between $i$ and $j$ of the highway port and can choose $i$ to other points on the basis of the demand and the distance to reload. If $a_{i j k}^{\prime} \leq 2 q_{i j}^{\prime}$, then the kth one cannot complete all tasks between highway ports $i$ and $j$, and other vehicles should be selected to complete these tasks. To fulfill the demand for tractor and semitrailer transportation between 
highway ports $i$ and $j .2 \frac{q_{i j}^{\prime}}{a_{i j k}^{\prime}}$ tractors are used. Vehicles with surplus capacity can still perform other tasks.

Stage 2: Vehicle scheduling of the cycled tractor and semitrailer transportation in the entire network.

If $q_{i j}$ is not divided into two parts $q_{i j}^{\prime}$ and $q_{j i}^{\prime}$, that is, given the requirement $q_{i j}$ directly, then a pure network tractor and semitrailer transportation vehicle scheduling algorithm can be designed according to the idea of this stage. At this stage, $q_{i j}^{\prime \prime}$ is scheduled, some tractors may be unloaded. During tractor dispatching, the ideal condition is that the tractor can continue to carry out the loaded tractor and semitrailer operations of the next line after completing the task of one line. Therefore, the line with the least remaining demand is selected to carry out the tractor transportation at this stage, and the starting point $i$ of a singular demand is taken as the starting point of the tractor. If the distance between $i$ and $j$ of highway port $d_{i j}$ is long and the tractor can complete only one trip within the working time $T$ of a day, then $q^{\prime \prime}{ }_{i j}$ tractors are needed from highway ports $i$ to $j$ for the traction trip. If distance $d_{i j}$ between highway ports $i$ and $j$ is short, then multiple traction trips can be completed in time $T_{k}$. Therefore, the demand for tractor and semitrailer transportation from $i$ to $j$ is only $q_{i j}^{\prime}$ between $i$ and $j$ at this stage, and $q_{j i}^{\prime \prime}=0$. After tractor $k$ completes the task from $i$ to $j$ once, it does not need to go back and seeks out point $l$ with the largest demand and the longest distance from highway port $j$ to other points in the next path. If $\frac{d_{i j}+d_{j l}}{v_{1}} \leq T$, then tractor $k$ can continue to complete the task in the next path. If $\frac{d_{i j}+d_{j l}}{v_{1}}>T$, then tractor $k$ does not perform the task

from $j$ to $l$. Instead, we need to select the point with the demand for tractor and semitrailer transportation and the second longest distance.

\subsubsection{Heuristic Algorithm Design}

$q_{i j}$ is divided into two parts: $q_{i j}^{\prime}$ and $q^{\prime \prime}{ }_{i j}$.

Stage 1: Schedule the demand $q^{\prime}{ }_{i j}$.

Step 1: Set the initial parameters, $i=1, K=0$ and $Z_{\mathrm{h}}=$ $0, Z_{\mathrm{e}}=0, Z_{\mathrm{c}}=0$.

Step 2: Select $q_{i j}^{\prime}>0$, and $\max \left(d_{i j}\right)$ corresponds to highway port $i ; j$ is the start point and end point of the first vehicle. If $q_{i j}^{\prime}>0$ and $d_{i j} \geq v_{1} T$, then $K=K+2 q_{i j}^{\prime}$, $q_{i j}^{\prime}=0=q_{j i}^{\prime}, Z_{\mathrm{h}}=Z_{\mathrm{h}}+2 q^{\prime}{ }_{i j} d_{i j} C_{i j}$, and $Z_{\mathrm{c}}=K_{\mathrm{c}}$. If $q_{i j}^{\prime}>0$,dij $\geq v_{1} T$, and $a_{i j k}^{\prime}=\left\lceil\frac{T v_{1}}{d_{i j}}\right\rceil>2 q^{\prime}{ }_{i j}=q^{\prime}{ }_{i j}+q^{\prime}{ }_{j i}$, then $K=K+1$, $Z_{\mathrm{c}}=K_{\mathrm{c}}$, and $q_{i j}^{\prime}=q_{j i}^{\prime}$. If $q^{\prime \prime}{ }_{i j}>0$, then highway ports $i$ and $j$ are selected as the intermission transportation path. If enough working time remains, then 1 with the second shortest distance $\left(d_{j l}\right)$ of highway port $j$ is selected as the start point for the next tractor and semitrailer transportation point until no working is time left; then, $q^{\prime \prime}{ }_{i j}=q^{\prime \prime} i j-1$, $Z_{\mathrm{h}}=Z_{\mathrm{h}}+2 q^{\prime}{ }_{i j} d_{i j} C_{i j}+d_{i j} C_{i j}+d_{j l} C_{j l}+\ldots$. If $q^{\prime \prime}{ }_{i j}=0$, then 1 with the second smallest departure distance $\left(d_{i l}\right)$ of highway port $i$ is selected as the next tractor and semitrailer transportation point until no working time is left for the vehicle; the corresponding $q_{j l}^{\prime}=q_{j l}^{\prime}-1$,

$Z_{\mathrm{h}}=Z_{\mathrm{h}}+2 q^{\prime}{ }_{i j} d_{i j} C_{i j}+d_{i j} C_{i j}+d_{j l} C_{j l}+\ldots$. If $q_{i j}^{\prime}>0, d_{i j} \geq$

$v_{1} T$, and $a_{i j k 1}^{\prime}=\left\lceil\frac{T v_{1}}{d_{i j}}\right\rceil<2 q_{i j}^{\prime}=q_{i j}^{\prime}+q_{j i}^{\prime}$, then other

vehicles are arranged between highway ports $i$ and $j$, and the number of vehicles needed is $\left\lceil\frac{2 q_{i j}^{\prime}}{a_{i j k_{1}}^{\prime}}\right\rceil$. The vehicles with remaining capacity can still complete other tasks; thus, $q_{i j}^{\prime}=0=q_{j i}^{\prime}, K=K+\left\lceil\frac{2 q_{i j}^{\prime}}{a_{i j k}^{\prime}}\right\rceil, Z_{\mathrm{h}}=Z_{\mathrm{h}}+2 q_{i j}^{\prime} d_{i j} C_{i j}$ and $Z_{\mathrm{c}}=K_{\mathrm{c}}$.

Step 3: For all $i \in N, i=i+1$, if $q^{\prime}{ }_{i j}>0$, then return to Step 2; if all $q_{i j}^{\prime}=0$, then stop the calculation, and $Z_{1}^{\prime}=Z_{\mathrm{h}}$ $+Z_{\mathrm{c}}$.

Stage 2: Schedule the tractor and semitrailer transportation requirement $q^{\prime \prime} i j$ after the scheduling at the first stage.

Step 1: Choose $i \in N$.

Step 2: Select the highway ports $i, j$ with $q^{\prime \prime}{ }_{i j}>0$ as the scheduling demand point. If $d i j \geq v_{1} T$, then $K=K+q^{\prime \prime}{ }_{i j}, q^{\prime \prime}{ }_{i j}$ $=0, Z_{\mathrm{h}}=Z_{\mathrm{h}}+q^{\prime \prime}{ }_{i j} d_{i j} C_{i j}$ and $Z_{\mathrm{c}}=K_{\mathrm{c}}$. If $d_{i j} \geq v_{1} T$, then two strategies are available. In the first strategy, vehicle $k$ carries out a round trip between highway port $i$ and highway port $j$. The vehicle is loaded in the one-way trip and unloaded from highway port $j$ to $i$. If vehicle $k$ can finish the transportation of $q_{i j}^{\prime}$ in $T$, then $K=K+1, q^{\prime \prime}{ }_{i j}=$ $0, Z_{\mathrm{h}}=Z_{\mathrm{h}}+q^{\prime \prime}{ }_{i j} d_{i j} C_{i j}, Z_{\mathrm{e}}=Z_{e}+\left(q^{\prime \prime}{ }_{i j}-1\right) d_{i j} c_{i j}$, and $Z_{\mathrm{c}}=$ $K_{\mathrm{c}}$. If enough time is left, we can select port 1 with $q^{\prime \prime}{ }_{i j}>0$ of highway port $j$ as the next tractor and semitrailer transportation point. If vehicle $\mathrm{k}$ cannot finish the transportation of $q^{\prime \prime}{ }_{i j}$ in $T$, then other vehicles need to be dispatched to finish the task, and the number of vehicles needed to complete the task of transportation between highway ports $i$ and $j$ is $\left[\frac{\frac{q^{\prime \prime}{ }_{i j} d_{i j}}{v_{1}}+\frac{\left(q^{\prime \prime}{ }_{i j}-1\right) d_{j i}}{v_{2}}}{T}\right]$. If the remaining capacity of the vehicle is still available for other tasks, then $K=K+\left[\frac{\frac{q^{\prime \prime}{ }_{i j} d_{i j}}{v_{1}}+\frac{\left(q^{\prime \prime}{ }_{i j}-1\right) d_{j i}}{v_{2}}}{T}\right], q^{\prime \prime}{ }_{i j}=0$, $Z_{\mathrm{h}}=Z_{\mathrm{h}}+q^{\prime \prime}{ }_{i j} d_{i j} C_{i j}, Z_{\mathrm{e}}=Z_{\mathrm{e}}+\left(q^{\prime \prime}{ }_{i j}-1\right) d_{i j} c_{i j}$ and $Z_{\mathrm{c}}=K_{\mathrm{c}}$. In the second strategy, vehicle $\mathrm{k}$ completes the task of tractor and semitrailer transportation in the highway port network. At this time, the vehicle is loaded and unloaded in the whole network. When vehicle $\mathrm{k}$ completes one trip from $i$ to $j$ of the highway port, $q^{\prime \prime}{ }_{i j}=q^{\prime \prime}{ }_{i j}-1$, port 1 with $q^{\prime \prime}{ }_{j l}>0$ of highway port $j$ is selected as the next point $q^{\prime \prime}{ }_{j l}=$ $q^{\prime \prime}{ }_{j l}-1$ until no working time is left, that is, $K=K+1$, $Z_{\mathrm{h}}=Z_{\mathrm{h}}+d_{i j} C_{i j}+d_{i j} C_{i j}+\ldots$. If all $q^{\prime \prime}{ }_{j l}=0$ start from highway port $j$, then the vehicle is unloaded to reach port 1 , and the highway port with the task of tractor and semitrailer 
transportation from port 1 is selected until no working time is left, that is, $K=K+1, Z_{\mathrm{h}}=Z_{\mathrm{h}}+d_{i j} C_{i j}+\ldots$, and $Z_{\mathrm{e}}=Z_{\mathrm{e}}+d_{j l} c_{j l}+\ldots$.

Step 3: For all $i \in N, i=i+1$, if $q^{\prime \prime}{ }_{i j}>0$, then return to Step 2; if all $q^{\prime \prime}{ }_{i j}=0$, then stop the calculation, and $Z^{\prime \prime}{ }_{1}=Z_{\mathrm{h}}$ $+Z_{\mathrm{e}}+Z_{\mathrm{c}}$.

In the third stage, the total cost of network scheduling is as follows: $Z_{1}=Z^{\prime}{ }_{1}+Z^{\prime \prime}{ }_{1}$.

\section{EXAMPLE ANALYSIS AND DISCUSSION}

In the Tianghui Highway Port, logistics enterprise L has transportation points in 10 cities. Enterprise managers want to solve the technical problem of vehicle scheduling of tractor and semitrailer transportation with the lowest cost.

Assume that the semitrailer's loaded and unloaded driving costs are $C_{i j}=0.8$ yuan $/ \mathrm{km}, c_{i j}=0.4$ yuan $/ \mathrm{km}$, respectively; the loaded and unloaded driving speeds of the tractor are $v_{1}=50 \mathrm{~km} / \mathrm{h}, v_{2}=70 \mathrm{~km} / \mathrm{h}$, respectively; the daily fixed cost is $c=500$ yuan; and the daily continuous working time is $T=16 \mathrm{~h}$. We check $d_{i j}$ by using Google Maps, as shown in Tab. 1. $q_{i j}$ is the randint function in MATLAB 2010a. The trailing transport tasks are generated among 10 customer points in $[0,10]$, and all tasks are integers, as shown in Tab. 2.

MATLAB 2010a is used for the program calculation. The results are shown in Tab. 3. The traditional method is to send one truck for a transport mission (this method is seldom used, but in this case, it is used for comparison). In the pure network transportation, transportation tasks in the whole network are assigned without division into two stages. A vehicle can carry out the next task as long as enough working time is left. It can be solved according to the idea of stage 2 in the heuristic algorithm.

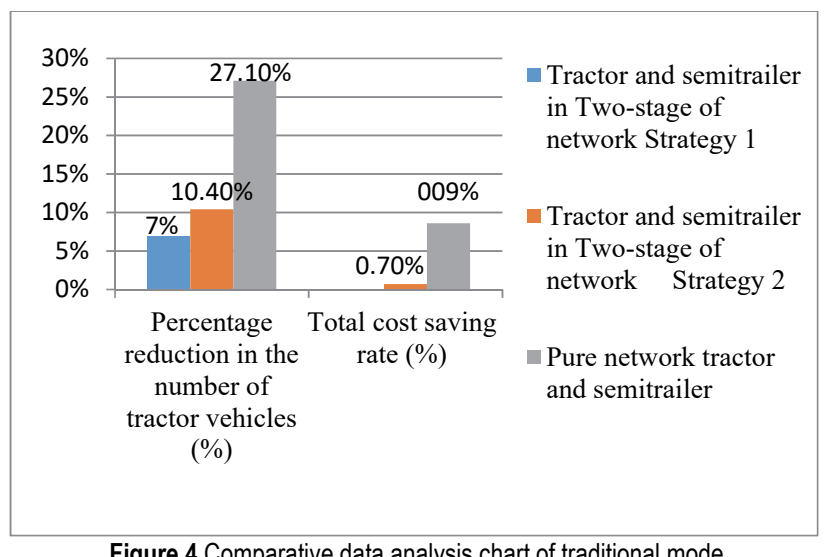

Figure 4 Comparative data analysis chart of traditional mode

Table 1 Distance between the highway and the port (unit: $\mathrm{km}$ )

\begin{tabular}{|c|c|c|c|c|c|c|c|c|c|c|c|}
\hline Order number & A & B & C & D & E & F & G & H & I & J \\
\hline A & 0 & 1218 & 680 & 120 & 290 & 1080 & 600 & 690 & 945 & 1010 \\
\hline B & 1218 & 0 & 540 & 1200 & 1500 & 2300 & 1710 & 1800 & 2000 & 2120 \\
\hline C & 680 & 540 & 0 & 660 & 960 & 1760 & 1170 & 1260 & 1170 & 1590 \\
\hline D & 120 & 1200 & 660 & 0 & 314 & 1108 & 525 & 609 & 818 & 930 \\
\hline E & 290 & 1500 & 960 & 314 & 0 & 816 & 402 & 586 & 846 & 964 \\
\hline F & 1080 & 2300 & 1760 & 1108 & 816 & 0 & 661 & 832 & 1131 & 1128 \\
\hline G & 600 & 1710 & 1170 & 525 & 402 & 661 & 0 & 274 & 594 & 600 \\
\hline H & 690 & 1800 & 1260 & 609 & 586 & 832 & 274 & 0 & 323 & 356 \\
\hline I & 945 & 2000 & 1170 & 818 & 846 & 1131 & 594 & 323 & 0 & 276 \\
\hline J & 1010 & 2120 & 1590 & 930 & 964 & 1128 & 600 & 356 & 276 & 0 \\
\hline
\end{tabular}

Table 2 Demand for tractor and semitrailer transportation between highways and ports (vehicles)

\begin{tabular}{|c|c|c|c|c|c|c|c|c|c|c|c|c|}
\hline Order number & $\mathrm{A}$ & $\mathrm{B}$ & $\mathrm{C}$ & $\mathrm{D}$ & $\mathrm{E}$ & $\mathrm{F}$ & $\mathrm{G}$ & $\mathrm{H}$ & $\mathrm{I}$ & $\mathrm{J}$ \\
\hline $\mathrm{A}$ & 0 & 7 & 8 & 0 & 1 & 4 & 6 & 2 & 0 & 1 \\
\hline B & 9 & 0 & 2 & 0 & 10 & 0 & 3 & 3 & 2 & 7 \\
\hline C & 1 & 3 & 0 & 5 & 0 & 9 & 8 & 5 & 8 & 5 \\
\hline D & 10 & 0 & 7 & 0 & 8 & 10 & 2 & 2 & 0 & 8 \\
\hline E & 6 & 1 & 9 & 10 & 0 & 5 & 7 & 9 & 10 & 7 \\
\hline F & 1 & 9 & 10 & 1 & 9 & 0 & 2 & 2 & 8 & 9 \\
\hline G & 3 & 7 & 6 & 6 & 0 & 3 & 0 & 2 & 5 & 9 \\
\hline H & 6 & 3 & 1 & 5 & 4 & 9 & 6 & 0 & 6 & 3 \\
\hline I & 10 & 10 & 1 & 0 & 2 & 4 & 8 & 2 & 0 & 7 \\
\hline J & 10 & 0 & 2 & 3 & 8 & 1 & 0 & 4 & 5 & 0 \\
\hline
\end{tabular}

Table 3 Comparison of calculation results

\begin{tabular}{|l|c|c|c|c|}
\hline \multicolumn{1}{|c|}{ Project } & \multirow{2}{*}{ Traditional mode } & Tractor and semitrailer in two-stage network & \multirow{2}{*}{$\begin{array}{c}\text { Pure network tractor and } \\
\text { semitrailer }\end{array}$} \\
\cline { 3 - 5 } & & Strategy 1 & Strategy 2 & 315 \\
\hline Tractor $K$ / number & 432 & 402 & 387 & 27.1 \\
\hline $\begin{array}{l}\text { Percentage reduction in the number of tractor } \\
\text { vehicles / \% }\end{array}$ & - & 7 & 10.4 & 329576 \\
\hline Loaded cost / yuan & 329576 & 329576 & 18576 & 11564 \\
\hline Unloaded cost / yuan & 0 & 10467 & 193500 & 157500 \\
\hline Fixed cost / yuan & 216000 & 201000 & 541702 & 498640 \\
\hline Total cost / yuan & 545576 & 541043 & 0.7 & 8.6 \\
\hline Total cost saving rate / \% & - & 0.8 & & 27 \\
\hline
\end{tabular}

Tab. 3 shows that the cost and number of tractors needed in the traditional method are lower than those in the two-stage and pure network tractor and semitrailer transportation. The results are shown in Fig. 4. Relative to that in the traditional mode, the numbers of tractors for tractor and semitrailer transportation in a two-stage 
network under Strategies 1 and 2 and that in a pure network decrease by $7 \%, 10.4 \%$, and $27.1 \%$, respectively; and the costs decrease by $0.8 \%, 0.7 \%$, and $8.6 \%$, respectively. Unlike that in the traditional method, the tractor in the twostage and pure network is allowed to pull multiple tasks if possible, thereby limiting the number of tractors needed. When the increased cost of unloaded driving is less than the fixed cost saved because of a decrease in the number of tractors, the transportation costs of the two types of tractor and semitrailer transportation decrease.

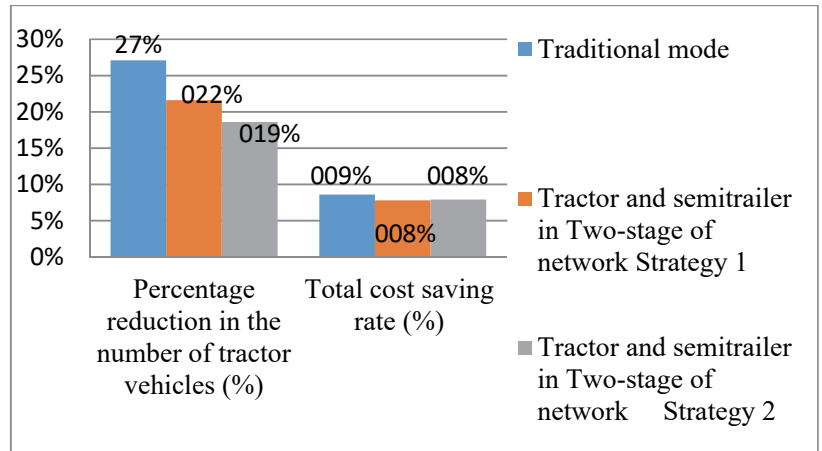

Figure 5 Comparative data analysis chart of tractor and semitrailer transportation for a pure network

The tractor and semitrailer transportation for the pure network is better than that for the two-stage network in terms of the number of tractors and costs. The results are shown in Fig. 5. Relative to the tractor and semitrailer transportation for the two two-stage network under Strategies 1 and 2 and the traditional method, the number of tractors in the tractor and semitrailer transportation for the pure network is reduced by $21.6 \%, 18.6 \%$, and $27 \%$, respectively; and the cost decreases by $7.8 \%, 7.9 \%$, and $8.6 \%$, respectively. Scheduling optimization in the whole network can effectively reduce the number of tractors and the total cost. In other words, the operator should change the original two-stage network mode and optimize network scheduling to achieve superior operation performance and thereby decrease the cost and enhance the profits.

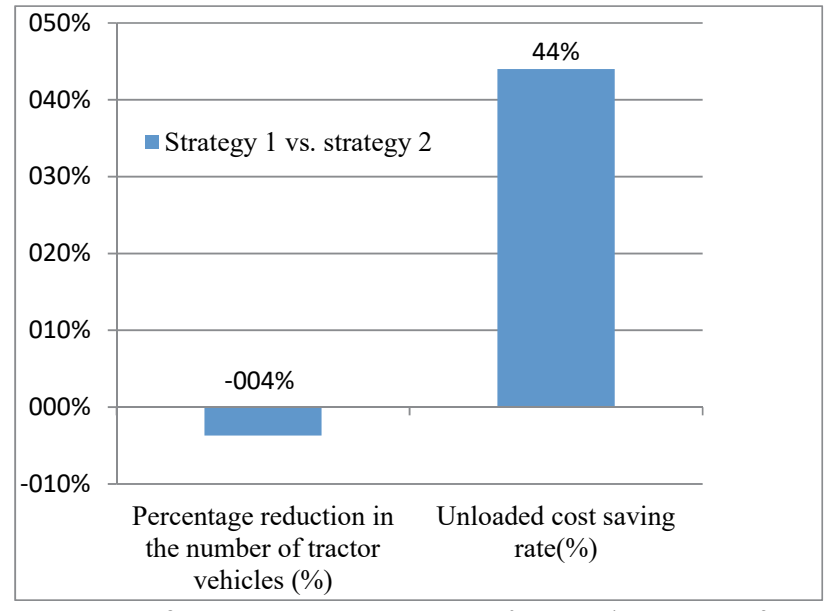

Figure 6 Comparative data analysis chart of strategy 1 and strategy 2

The two strategies of tractor and semitrailer transportation for the two-stage network are compared. The scheduling of the whole network is optimized in Stage 2 of strategy 2. Meanwhile, in Stage 2 of strategy 1, the two ends are first optimized, followed by the whole network.
This result verifies that the vehicle scheduling for the entire network can reduce the number of tractors. Although the number of tractors in strategy 2 is $3.7 \%$ less than that in strategy 1 , the unloading cost of strategy 2 is $44 \%$ higher than that of strategy 1 . Therefore, strategy 1 is slightly superior to strategy 2 in terms of cost performance.

\section{CONCLUSION}

To explore optimal scheduling and address the TSRP under network conditions, this study considered unbalanced demands and the existence of multiple needs on the basis of the characteristics of highway ports. To minimize the transportation cost and the number of tractors, we established a two-objective optimization model for scheduling the tractor and semitrailer transportation in the network. A heuristic algorithm was also designed to solve the problem. The following conclusions could be drawn:

(1) Relative to the traditional transportation mode, the optimization of tractor and semitrailer transportation in the network can reduce the number of tractors and the overall transportation cost.

(2) In network transportation, scheduling optimization across the entire network can reduce the number of tractors and the transportation costs effectively.

Considering the unbalanced demands between both ends and the possibility of multiple demands in actual transportation, this study proposed to optimize vehicle scheduling across the entire highway port network. This approach is applicable to actual situations and can help transport enterprises to enhance their economic benefits. This study assumes that the number of semitrailers in all highway ports is enough, that is, unloaded semitrailers are not scheduled, and the situation of several types of tractors and trailers available are not considered; this scenario is contrary to actual operations. These details will be considered in our future research.

\section{REFERENCES}

[1] Semet, F. (1993). Taillard E. Solving real-life vehicle routing problems efficiently using tabu search. Annals of Operations Research, 41(4), 469-488. https://doi.org/10.1007/BF02023006

[2] Li, Y. (2004). Semi-trailer transport:An effective way to improve road transport efficiency. Journal of highway and transportation research and development, 21(4), 119-122.

[3] Barcos, L., Rodriguez, V., \& Alvarez,M.J. (2010).Routing Design for Less-than-truckload Motor Carriers Using Ant Colony Optimization. Transportation Research Part E: Logistics and Transportation Review, 46(3), 367-383. https://doi.org/10.1016/j.tre.2009.11.006

[4] Li, H., Li, Y., \& Zhao, Q. (2013). The Tractor and Semitrailer Routing Considering Carbon Dioxide Emissions. Mathematical Problems in Engineering, Article ID 509160, 1-12. https://doi.org/10.1155/2013/509160

[5] Li, H., Li Y., \& Lv, Y. (2013).The Effects of the Tractor and Semitrailer R outing Problem on Mitigation of Carbon Dioxide Emissions. Discrete Dynamics in Nature \& Society, 1-414. https://doi.org/10.1155/2013/809135

[6] Semet F. \& Taillard, E. (1993). Solving real-life vehicle routing problems efficiently using tabu search. Annals of Operations Research, 41(4), 469-488. https://doi.org/10.1007/BF02023006 
[7] Meulemeester, L. D., Laporte G., \& Louveaux F. V. (1997) Optimal sequencingof skip collections and deliveries. Journal of the Operational Research Society, 48(1), 57-64. https://doi.org/10.1057/palgrave.jors.2600325

[8] Batsyn, M. \& Ponomarenko, A. (2014). Heuristic for a Reallife Truck and Trailer Routing Problem. Procedia Computer Science, 31, 778-792. https://doi.org/10.1016/j.procs.2014.05.328

[9] Chao, I. M. (2002). A tabu search method for the truck and trailer routing problem. Computers \& Operations Research, 29(1), 33-51. https://doi.org/10.1016/S0305-0548(00)00056-3

[10] Isis, T. P., Carlos, C. C., Alejandro, R., \& José, L. V. (2016). A characterization of the Performance of ordering Methods in TTRP with fuzzy coefficients in the capacity constraints, 2016 International Conference on Information Processing \& Management of Uncertainty in Knowledge-based Systems (IPMU). Eindhoven, Netherlands: Final Program \& Book of Abstracts.

[11] Isis, T. P., Carlos Cruz, C., Alejandro, R., \& José, L. V. (2017). Applied data mining in TTRP with fuzzy demands and capacities. Revista Investigaciono Peracional, 38(2), 195-205.

[12] Peng, Y. \& Gao, H. (2020). Path optimization of multitripswap-bodyvehicle routing problem with time window. Journal of Transportation Systems Engineering and Information Technology, 20(1), 166-174.

[13] Yang, Z., Xv, Q., Chen, Z. X., \& Jin, Z. H. (2015). Multiple Tractor-and-trailerCrossed Scheduling Optimization under Hybrid Mode. Journal of Transportation Systems Engineering and Information Technology, 15(6), 140-146.

[14] Parragh, S. N. \& Cordeau, J. F. (2017). Branch-and-price and adaptive large neighborhood search for the truck and trailer routing problem with time windows. Computers \& Operations Research, 83, 28-44. https://doi.org/10.1016/j.cor.2017.01.020

[15] Toffolo, T. A. M., Christiaens, J., \& Malderen, S. V. (2018). Stochastic local search with learning automaton for the swap-bodyvehicle routing problem. Computers \& Operations Research, 89, 68-81. https://doi.org/10.1016/j.cor.2017.08.002

[16] Wang, C., Zhou, S., \& Gao, Y. (2018). A self-adaptive bat algorithm for the truck and trailer routing problem. Engineering Computations, 35(1), 108-135. https://doi.org/10.1108/EC-11-2016-0408

[17] Wang, C., Gao, Y., \& Liu, C. (2018). Solving TTRP problem based on an iterated variable neighborhood descent algorithm. Systems Engineering-Theory \& Practice, 11.38(11), 2892-2906.

[18] Bartolini, E. \& Schneider, M. (2020). A two-commodity flow formulation for the capacitated truck-and-trailer routing problem. Discrete Applied Mathematics, 275, 3-18. https://doi.org/10.1016/j.dam.2018.07.033

[19] Li, H., Lv, T., \& Li, Y. (2015). The tractor and smitrailer routing problem with many-to-many demand considering carbon dioxide emissions. Transportation Research Part DTransport and Environment, 34, 68-82. https://doi.org/10.1016/j.trd.2014.10.004

[20] Li, H., Chang, X., \& Zhao, W. (2017). The vehicle flow formulation and savings-based algorithm for the rollonrolloff vehicle routing problem. European Journal of Operational Reseach, 40(3), 867-872. https://doi.org/10.1016/j.ejor.2016.08.018

[21] Li, H., Jian, X., Chang, X., \& Lu, Y. (2018). Show more the generalized rollon-rolloff vehicle routing problem and savings-based algorithm Transportation Research Part B: Methodological, 113(7), 1-23. https://doi.org/10.1016/j.trb.2018.05.005

[22] Xue, Z., Lin, W., \& Miao, L. (2015). Local container drayage problem with tractor and trailer operating in separable mode.
Flexible Services and Manufacturing Journal, 27(2-3), 431450. https://doi.org/10.1007/s10696-014-9190-2

[23] Berghman, L. \& Leus, R. (2015). Practical solutions for a dock assignment problem with trailer transportation. European Journal of Operational Research, 246(3), 787799. https://doi.org/10.1016/j.ejor.2015.05.057

[24]Yang, L., Liu, J., \& Zhang, Y. (2020). An Intelligent Security Defensive Model of SCADA Based on Multi-Agent in Oil and Gas Fields. International Journal of Pattern Recognition and Artificial Intelligence, 34(01), 269-282. https://doi.org/10.1142/S021800142059003X

[25] Li, H.Q., Zhao, W. C., \& Li, Y. R. (2016). Trailer pick up tractor routing problem with timeliness requirement and solving. Journal of Traffic and Transportation Engineering, 16(5), 95-102.

[26] Yu, L., Lin, H., \& Chen, B. R. (2014). Research of Vehicle Scheduling Problem of the Network Drop and Pull Transport. Journal of Transportation Engineering systems and Information, 12(2), 58-64.

[27] Yang, G. M. \& Luo, Z. Y. (2016). Scheduling optimization of container tractor-and-trailer transportation under hubspoke network. Journal of Dalian Maritime University, 42(3), 63-69.

[28] Yang, L., Geng, X., \& Liao, H. (2016). A web sentiment analysis method on fuzzy clustering for mobile social media users. Eurasip Journal on Wireless Communications \& Networking, 128(1), 1-13. https://doi.org/10.1186/s13638-016-0626-0

[29] Cristina, M. V., Elena, V. R., Valentín, J., \& Césa, O. G. (2019). A bimmodel from reality capture data. DYNA, 94(3), $1-6$.

\section{Contact information:}

Hongxia GUO, PhD candidate, Associate Professor

1) School of Transportation and Logistics, Southwest Jiaotong University, China,

2) School of Economics and Management,

Guangxi University of Science and Technology, China,

Building 33, South Asia Mansion, 3 Wenchang Road,

Liuzhou, Guangxi, 545006 P. R. China

E-mail: jtxguohongxia@126.com

\section{Shaoquan NI, PhD, Professor}

(Corresponding author)

School of Transportation and Logistics,

Southwest Jiaotong University, China,

No. 111, Section 1, North 2nd Ring Road, Jinniu District, Chengdu, China

E-mail: shaoquanni@switu.edu.cn 